$\begin{aligned} & \text { Birthday honours } \\ & \text { Alfred Nobel's prizes } \\ & \text { celebrate their } \\ & \text { centenary } \\ & \text { p553-554 }\end{aligned}$
$\begin{aligned} & \text { Balls of ire } \\ & \text { Transgenic cotton } \\ & \text { found growing } \\ & \text { wild in India } \\ & p 555\end{aligned}$

\title{
Trio united by division as cell cycle clinches centenary Nobel
}

\& Bernd Pulverer, London

The 2001 Nobels mark the centenary of the most prestigious prizes in science. So it is fitting that this year's award for physiology or medicine goes to three biologists who revealed the mysteries of a process central to the growth, development and maintenance of all living organisms: cell division.

Leland Hartwell, president and director of the Fred Hutchinson Cancer Research Center in Seattle, Paul Nurse, director-general of the Imperial Cancer Research Fund (ICRF) in London, and Tim Hunt, also of the ICRF, have been honoured for their contributions to our understanding of the cell cycle.

The molecular machinery underlying the cycle of cell growth and division remained obscure until the early 1970s, when Hartwell's pioneering work gave the first glimpses of the processes involved.

Working with baker's yeast, Saccharomyces cerevisiae, Hartwell set out to identify the genes involved in regulating the cell cycle. In a series of papers, he isolated yeast mutants that stopped at certain points in the cell cycle if the temperature was changed.

Hartwell identified more than 100 celldivision-cycle (CDC) genes, including one, dubbed CDC28 or start, that seemed to initiate the copying of a cell's DNA, the step that precedes cell division. He went on to show that there was a striking interdependence between the events controlled by the various CDC genes - one would have to be completed before the subsequent stages could begin.

Many researchers who today work on the cell cycle say they were inspired to enter the field by Hartwell's pioneering studies. "Without his fundamental insight, there would be no such thing as the cell-cycle field," says Jim Roberts, also at the Hutchinson centre.

By studying the sensitivity of yeast cells to irradiation, Hartwell in the late 1980s introduced the concept of 'checkpoints', and identified the first yeast genes involved. Checkpoints are control points at which regulatory proteins halt the cell cycle upon detecting damage to DNA, or other abnormalities, allowing repair before the cycle resumes. In their absence, cells would be
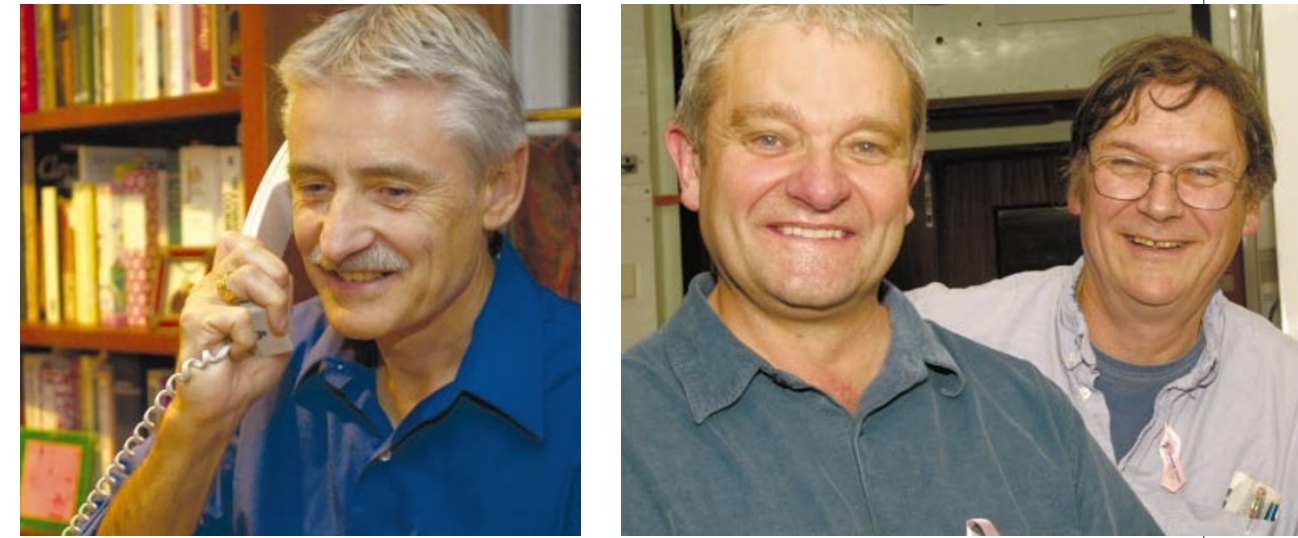

Cell celebrators: centenary laureates Leland Hartwell (left), Paul Nurse (centre) and Tim Hunt.

prone to genetic damage. Indeed, many forms of cancer have since been linked to problems with checkpoint control.

Shortly after Hartwell began identifying CDC genes, Nurse started working on another species of yeast, Schizosaccharomyces pombe. He identified mutants involved in regulating the cell cycle, and later showed that one, labelled $c d c 2$, was functionally equivalent to start. $C D C 28$ and $c d c 2$ have since been shown to encode enzymes belonging to the family of cyclin-dependent kinases (CDKs).

\section{Phenomenal success}

In 1987, Nurse isolated the corresponding gene in human cells, which encodes an enzyme later named CDK1. This, says Nurse, confirmed that biologists working on the cell cycle in yeast were identifying fundamental phenomena conserved by evolution across a wide range of organisms and validated the study of model organisms to gain insights into human biology. "The same gene controlled cell division in yeast and humans and hence everything in between," he says.

Hunt's contribution was the discovery, from studies of fertilized eggs of frogs and sea urchins, of a new class of proteins that he called cyclins. The activity of CDKs was later found to depend on their association with these proteins.

In 1983, Hunt showed that the cyclins disappeared just before cell division, and immediately realized that this was a key finding. "I knew I had made an important discovery," he says. Protein degradation has since emerged as an important general phenomenon in cell-cycle regulation.

Contacted by Nature on 8 October shortly after receiving the phone call from Stockholm, Nurse and Hunt were in ecstatic mood, with champagne corks popping in the background. At a press conference later in the day, Nurse admitted that the news had him "running around like a headless chicken". Hunt added that it only sunk in after he had checked the citation on the Nobel website.

But as is often the case, the rule that restricts Nobel awards to three winners (see pages 560-564) means that other pivotal figures go unrewarded. "If anyone will be slightly disappointed, it will be Yoshio Masui," Nurse told Nature. In the 1970s, Masui, now a professor emeritus at the University of Toronto, found that an extract from frog eggs, called maturation-promoting factor, readied the eggs for their first cell division. This was later found to be composed of the CDK encoded by $c d c 2$ and a cyclin.

But researchers in the field agree that Hartwell, Nurse and Hunt are worthy winners. "I call Hartwell the 'father', Nurse the 'great preacher' and Hunt the 'artist' of cell division," says Mitsuhiro Yanagida of Kyoto University in Japan.

Additional reporting by Erica Klarreich.

www.nobel.se 